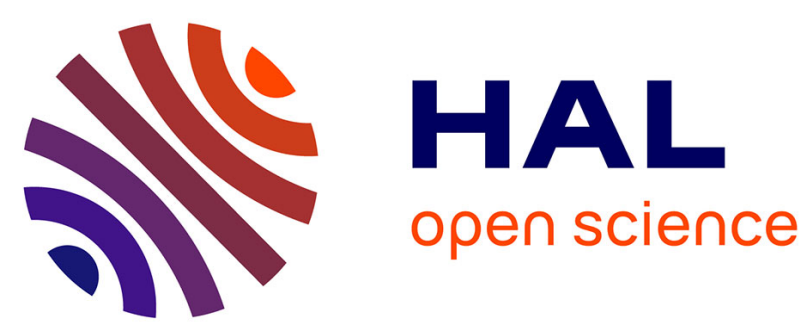

\title{
Frequency and Predictors for the Risk of Stroke Recurrence up to 10 years after stroke: The South London Stroke Register
}

Keerthi Michelle Mohan, Siobhan Laura Crichton, Andrew Peter Grieve, Anthony George Rudd, Charles David Alexander Wolfe, Peter Ulrich

Heuschmann

\section{To cite this version:}

Keerthi Michelle Mohan, Siobhan Laura Crichton, Andrew Peter Grieve, Anthony George Rudd, Charles David Alexander Wolfe, et al.. Frequency and Predictors for the Risk of Stroke Recurrence up to 10 years after stroke: The South London Stroke Register. Journal of Neurology, Neurosurgery and Psychiatry, 2009, 80 (9), pp.1012. 10.1136/jnnp.2008.170456 . hal-00552758

\section{HAL Id: hal-00552758 https://hal.science/hal-00552758}

Submitted on 6 Jan 2011

HAL is a multi-disciplinary open access archive for the deposit and dissemination of scientific research documents, whether they are published or not. The documents may come from teaching and research institutions in France or abroad, or from public or private research centers.
L'archive ouverte pluridisciplinaire HAL, est destinée au dépôt et à la diffusion de documents scientifiques de niveau recherche, publiés ou non, émanant des établissements d'enseignement et de recherche français ou étrangers, des laboratoires publics ou privés. 
Frequency and Predictors for the Risk of Stroke Recurrence up to 10 years after stroke: The South London Stroke Register

Authors

Keerthi Michelle Mohan, $\mathrm{MRCP}^{1}$

Siobhan Laura Crichton $\mathrm{MSc}^{1}$

Andrew Peter Grieve, PhD, DSc ${ }^{1}$

Anthony George Rudd, FRCP ${ }^{2}$

Charles David Alexander Wolfe, FFPH ${ }^{1,3}$

Peter Ulrich Heuschmann, MD, MPH ${ }^{1,3}$

\section{Authors' affiliations}

${ }^{1}$ King's College London, Division of Health and Social Care Research, London, UK

${ }^{2}$ Department of Health and Ageing, Guy's and St. Thomas' NHS Foundation Trust,

St. Thomas' Hospital. London, U.K.

${ }^{3}$ NIHR Biomedical Research Centre, Guy's and St. Thomas ‘ NHS Foundation Trust and King's College London, London, U.K.

\section{Correspondence to:}

K. Mohan, King's College London, Division of Health and Social Care Research,

$7^{\text {th }}$ Floor Capital House, 42 Weston St, London SE1 3QD, UK.

Email: kitty.mohan@kcl.ac.uk

Telephone: 0044 (0)20 78486614 Fax: 0044 (0)20 78486620

Keywords: $\quad$ Stroke, long-term, recurrence, predictors.

Word count: 2991 


\section{ABSTRACT}

Background -Data estimating the risk of, and predictors for long-term stroke recurrence are lacking.

Methods-Data were collected from the population-based South London Stroke Register. Patients were followed up for a maximum of 10 years. Kaplan-Meier estimates and Cox Proportional Hazards models were used to assess cumulative risk of and predictors for first stroke recurrence. Variables analysed included sociodemographic factors, stroke subtype (defined as cerebral infarction, intracerebral haemorrhage and subarachnoid haemorrhage), stroke severity markers and prior-tostroke risk factors.

Results- Between 1995 and 2004, 2874 patients with first-ever stroke were included. Mean follow-up period was 2.9 years. During 8311 person-years of follow up, 303 recurrent events occurred. The cumulative risk of stroke recurrence at 1 year, 5 years and 10 years was $7.1 \%, 16.2 \%$ and $24.5 \%$ respectively. No differences in stroke recurrence were noted between the stroke subtypes. Factors increasing the risk of recurrence at 1 year, were previous myocardial infarction (HR 1.73; 95\% CI 1.082.78) and atrial fibrillation (HR 1.61; 95\% CI 1.04-4.27); at 5 years, hypertension (HR 1.47; 95\% CI 1.08-1.99) and atrial fibrillation (HR 1.79; 95\% CI 1.29-2.49); and at 10 years, older age $(\mathrm{p}=0.04)$, and hypertension (HR 1.38, 95\% CI 1.04-1.82), myocardial infarction (HR 1.50, 95\% CI 1.06-2.11), and atrial fibrillation (HR 1.51, 95\% CI 1.09-2.09).

Conclusions-Very long-term risk of stroke recurrence is substantial. Different predictors for stroke recurrence were identified throughout the follow-up period. Risk factors prior to initial stroke have a significant role in predicting stroke recurrence up to 10 years. 


\section{INTRODUCTION}

Recurrent strokes are more likely to be disabling or fatal than first ever strokes ${ }^{1}$. Previous long-term studies up to 5 years post-stroke show great variation in recurrence rates ranging from 12 to $42 \%$. These variations may be caused by different selection of study samples, (e.g.) hospital based, population based or clinical trial populations or due to differing methodology used. Predictors for stroke recurrence remain largely unknown with socio-demographic factors, co-morbidities and stroke subtype identified as important predictors in different studies ${ }^{4-6}$. It is not clear if predictors of long-term recurrence are different to predictors of stroke recurrence in the early years post stroke.

The aim of this study is to estimate the risk and predictors of long-term first stroke recurrence up to 10 year post initial stroke within a population based setting.

\section{METHODS}

\section{Study Area and Population}

The South London Stroke Register (SLSR) is a population-based stroke register recording first ever strokes in patients of all age groups for a defined area of South London. The total source population was 271817 with $63 \%$ white, $28 \%$ black and $9 \%$ of other ethnic groups at the time of Census 2001. Since 1995, the SLSR has been monitoring incidence rates, cause, risk factors and long-term outcomes after stroke. The data reported in the present study were based on the 2874 cases registered between January 11995 and December 312004.

\section{Case ascertainment}


The methodology has been described in detail previously and is summarised below.; Sixteen overlapping referral sources were used to increase completeness of notification. All patients with a suspected diagnosis of first or recurrent stroke, as defined below, were identified by one of the sources of notification and investigated for eligibility of study inclusion. Hospital surveillance of admissions for stroke included two teaching hospitals within and three outside the study area. Patients admitted to hospitals serving the study area were identified by daily reviews of acute wards serving stroke patients, weekly checks of brain imaging referrals and outpatient Neurovascular Clinic attendance, and monthly reviews of bereavement records and of bed movement records. For identifying patients not admitted to hospital all general practitioners (GPs) within and on the borders of the study area were contacted regularly and asked to notify all stroke patients. Completeness of case ascertainment was estimated to be between $75-84 \%$ over the 10 year period ${ }^{7 ; 8}$.

\section{Data collection}

Specially trained fieldworkers collected all data prospectively. The diagnosis of stroke was verified by a study physician. Face-to-face follow-up visits were carried out at 3 months, 1 year, and then annually post-initial stroke. All patients were asked at every follow-up if they experienced another stroke. Registration of first stroke recurrence was performed in the same way as the initial stroke ${ }^{4}$.

\section{Variable definition}

Stroke was defined according to the World Health Organisation (WHO) criteria. ${ }^{9}$ The pathological subtype of stroke was classified as cerebral infarction (CI), primary intracerebral haemorrhage (PICH), subarachnoid haemorrhage (SAH) or undefined 
(UND). Classification was based on results from at least one of the following: brain imaging performed within 30 days of stroke (computerised tomography or magnetic resonance imaging), analysis of cerebrospinal fluid (in all living patients with subarachnoid haemorrhage in whom brain imaging was not diagnostic) or necropsy examination.

The definition of stroke recurrence was the same as for the index stroke. Additionally, clinical diagnosis of a new neurological deficit, or deterioration of a previous deficit not due to oedema, haemorrhagic transformation, or intercurrent illness was required. Only recurrences 21 days after the initial event, or if earlier, clearly in a different vascular territory were included. The same referral sources were used for notification of stroke recurrences as for initial stroke ascertainment. All patients were eligible for follow-up if alive and having reached the specified point of follow-up by March 2008

As potential predictors of stroke recurrence, the following variables were selected. Demographic factors included age (categorised as $<65,65-74,>75$ ), gender, ethnicity (categorised as white, black and other) and socio-economic status. Socioeconomic status categories were grouped into non-manual (I, II, and III non-manual) or manual (III manual, IV, and V) according to the patient's current (or for the retired and others not currently working, the most recent) employment. Co-morbidities included history of transient ischaemic attack (TIA), ischaemic heart disease, atrial fibrillation (AF), hypertension, diabetes mellitus and smoking. Smoking status was recorded as current smoker or non- or ex-smoker. 
Stroke severity was defined as the presence of neurological deficit during the acute phase of the initial stroke. Case severity variables included motor deficit, urinary incontinence, and Glasgow coma score (categorised as 3-8, 9-12, 13-15) ${ }^{10}$.

\section{Statistical analyses}

Descriptive and univariate analyses using Kaplan-Meier estimates were used to model the risk of recurrent stroke (1- survival free of recurrent stroke) and therefore to measure the cumulative risk of stroke recurrence and $95 \%$ confidence intervals $(\mathrm{CI})$ at 1, 5 and 10 years post initial stroke. For each variable individually, hazard ratios (HR) and the corresponding 95\% confidence intervals (CI) were estimated using Cox regression analyses. The assumption of proportional hazards was assessed using log minus log survival plots. Patients were censored at time of death, if lost to follow-up, or if alive at 10 years after stroke.

In the multivariate analyses, the influence of demographics, pathological subtype of the initial event, stroke severity, and co-morbidities as predictors of stroke recurrence were investigated. When analysing age, the broad $>75$ category was used due to the small numbers of patients surviving to long term follow up who were in higher age groups. Variables in multivariable analyses were eliminated using the backward elimination procedure. Possible interactions between age, stroke subtype and comorbidities were controlled by adding terms of interaction to the regression model. Multivariable analyses were restricted to patients without missing values, which totalled 2268 patients. The number of patients with missing values ranged from 0 for the age, gender and stroke subtype variables, to $254(8.8 \%)$ for incontinence at time of initial stroke. 
A sensitivity analysis was performed with patients censored at time of follow-up rather than at date of death, if death occurred more than 1 year after last follow-up.

All tests were two-tailed and $\mathrm{p}$ values $<0.05$ were regarded as statistically significant. Statistical analyses were performed using STATA software version 10(SE) and SPSS version 16.1 .

\section{Ethics}

Patients or their relatives gave written informed consent to participate in the study. The design of the study was approved by the ethics committees of Guy's and St. Thomas' Hospital Trust, King's College Hospital, Queens Square and Westminster Hospital (London).

\section{RESULTS}

This study included a total of 2874 first-ever stroke patients registered between January 1995 and December 2004. The mean follow-up time was 2.9 years, with a median time of 1.93 years and a total of 8310.5 person years of follow-up included. During this period, 303 recurrent strokes were documented. Of the 2874 patients eligible for follow-up at 1 year, 1042 had died; at 5 years, 2447 patients were eligible for follow-up, of whom 1304 had died; and at 10 years, 1044 patients were eligible for follow-up, of whom 696 had died. Patient characteristics at time of initial stroke are presented in Table 1. 
Table 1: Descriptive Statistics

\begin{tabular}{|c|c|}
\hline & Total, N(\%) \\
\hline Total & 2874 \\
\hline \multicolumn{2}{|l|}{ Age group } \\
\hline$<65$ & $863(30.0)$ \\
\hline $65-74$ & $764(26.6)$ \\
\hline $75-84$ & $1247(43.4)$ \\
\hline \multicolumn{2}{|l|}{ Gender } \\
\hline Female & $1447(50.3)$ \\
\hline \multicolumn{2}{|l|}{ Ethnicity } \\
\hline White & $2126(75.8)$ \\
\hline Black & $525(18.7)$ \\
\hline Other & $153(5.5)$ \\
\hline \multicolumn{2}{|l|}{ Socio economic status } \\
\hline Non-manual & $730(25.4)$ \\
\hline Manual & $1604(55.8)$ \\
\hline Unknown & $540(18.8)$ \\
\hline \multicolumn{2}{|l|}{ Stroke Subtype } \\
\hline Infarct & 2089(72.7) \\
\hline $\mathrm{PICH}$ & $395(13.7)$ \\
\hline SAH & $171(6.0)$ \\
\hline Undefined & 219(7.6) \\
\hline \multicolumn{2}{|l|}{ Risk factors } \\
\hline Previous TIA & $358(13.4)$ \\
\hline Hypertension & $1714(64.1)$ \\
\hline Diabetes Mellitis & $483(18.0)$ \\
\hline Previous MI & $315(11.7)$ \\
\hline Previous AF & $463(17.2)$ \\
\hline Smoker or ex-smoker & $943(35.6)$ \\
\hline \multicolumn{2}{|l|}{ Stroke severity Indices } \\
\hline GCS $<8$ & $497(18.1)$ \\
\hline $9-12$ & $422(15.3)$ \\
\hline $13-15$ & $1835(66.6)$ \\
\hline Motor deficit & $2282(84.4)$ \\
\hline Incontinence & $1238(47.3)$ \\
\hline
\end{tabular}

\section{Survival Analyses}

The cumulative risk of first stroke recurrence at 1 year, 5 years and 10 years was $7.1 \%$ (95\% CI 6.0 to $8.3 \%), 16.2 \%$ (95\% CI 14.4 to $18.1 \%$ ) and $24.5 \%$ (95\% CI 21.3 to 
$27.9 \%$ ) respectively. Table 2 shows the univariate analyses of cumulative risk of stroke recurrence up to 10 years.

Table 2: Univariate analyses: cumulative risk of stroke recurrence

\begin{tabular}{|c|c|c|c|}
\hline & \multicolumn{3}{|c|}{ Cumulative risk of recurrence, $\%(95 \% \mathrm{CI})$} \\
\hline & At 1 year & At 5 years & At 10 years \\
\hline Total & $7.1(6.0-8.3)$ & $16.2(14.4-18.1)$ & $24.5(21.3-27.9)$ \\
\hline \multicolumn{4}{|l|}{ Age group } \\
\hline$>65$ & $6.2(4.6-8.3)$ & $12.6(10.1-15.6)$ & $17.2(13.8-21.4)$ \\
\hline $65-74$ & $6.6(4.8-9.0)$ & $16.2(13.1-20.0)$ & $29.6(23.4-36.8)$ \\
\hline$>75$ & $8.4(6.6-10.6)$ & $20.4(17.0-24.5)$ & $30.1(21.3-41.4)$ \\
\hline \multicolumn{4}{|l|}{ Gender } \\
\hline Male & $6.0(4.7-7.6)$ & $15.5(13.1-18.2)$ & $22.9(19.1-27.4)$ \\
\hline Female & $8.4(6.8-10.4)$ & $17.1(14.4-20.1)$ & $26.4(21.5-32.2)$ \\
\hline \multicolumn{4}{|l|}{ Ethnicity } \\
\hline White & $7.4(6.2-8.9)$ & $16.1(14.0-18.5)$ & $25.1(21.2-29.5)$ \\
\hline Black & $6.1(4.1-8.8)$ & $16.7(13.0-21.3)$ & $23.7(18.4-30.2)$ \\
\hline Other & $7.7(4.1-14.2)$ & $15.7(9.7-24.6)$ & $20.8(12.9-32.6)$ \\
\hline \multicolumn{4}{|l|}{ Socio economic status } \\
\hline Non-manual & $6.5(4.7-8.8)$ & $14.7(11.7-18.3)$ & $26.3(20.6-33.3)$ \\
\hline Manual & $7.7(6.3-9.3)$ & $17.5(15.1-20.2)$ & $24.9(21.0-29.3)$ \\
\hline Unknown & $5.9(3.2-11.0)$ & $14.5(9.3-22.3)$ & $17.0(10.6-26.5)$ \\
\hline \multicolumn{4}{|l|}{ Stroke Subtype } \\
\hline Infarct & $6.9(5.8-8.3)$ & $16.6(14.6-18.9)$ & $25.7(21.9-29.9)$ \\
\hline $\mathrm{PICH}$ & $7.7(4.8-12.2)$ & $16.5(11.6-23.1)$ & $19.5(13.6-27.6)$ \\
\hline $\mathrm{SAH}$ & $4.7(2.0-11.0)$ & $4.7(2.0-11.0)$ & $7.5(3.0-17.9)$ \\
\hline Undefined & $11.9(6.5-21.2)$ & $21.6(13.6-33.3)$ & $43.4(25.5-66.8)$ \\
\hline \multicolumn{4}{|l|}{ Risk factors } \\
\hline No TIA & $7.0(5.9-8.4)$ & $15.4(13.4-17.6)$ & $24.9(21.4-28.8)$ \\
\hline Previous TIA & $9.5(6.5-13.7)$ & $22.0(16.9-28.5)$ & $26.5(19.0-36.1)$ \\
\hline No Hypertension & $6.6(4.9-8.8)$ & $12.6(10.0-15.8)$ & $18.7(14.7-23.7)$ \\
\hline Hypertension & $7,8(6.4-9.5)$ & $18.4(16.0-21.1)$ & $27.8(23.6-32.5)$ \\
\hline No Diabetes Mellitis & $7.2(6.0-8.6)$ & $15.6(13.6-18.0)$ & $23.8(22.2-41.3)$ \\
\hline Diabetes Mellitis & $8.4(5.9-11.9)$ & $20.0(15.6-25.3)$ & $30.6(22.2-41.3)$ \\
\hline No MI & $6.9(5.8-8.3)$ & $15.7(13.7-17.8)$ & $23.4(20.1-27.1)$ \\
\hline Previous MI & $11 / 3(7.7-16.6)$ & $22.6(16.6-30.3)$ & $41.1(29.1-55.8)$ \\
\hline No AF & $6.9(5.8-8.3)$ & $15.4(13.5-17.5)$ & $24.6(21.2-28.5)$ \\
\hline Previous AF & $9.9(6.8-14.3)$ & $24.7(18.6-32.4)$ & $27.5(20.0-37.1)$ \\
\hline Non-Smoker & $8.1(6.7-9.8)$ & $17.5(15.1-20.1)$ & $26.4(21.8-31.6)$ \\
\hline Smoker or ex-smoker & $5.4(4.0-7.4)$ & $13.9(11.2-17.1)$ & $21.0(17.1-25.6)$ \\
\hline \multicolumn{4}{|l|}{ Stroke severity } \\
\hline \multicolumn{4}{|l|}{ Indices } \\
\hline GCS $<8$ & $3.2(1.1-9.2)$ & $10.1(4.7-20.9)$ & $10.1(4.7-20.9)$ \\
\hline $9-12$ & $7.7(4.9-11.9)$ & $13.8(9.5-19.9)$ & $18.1(11.6-27.4)$ \\
\hline $13-15$ & $7.2(6.1-8.6)$ & $16.4(14.4-18.6)$ & $25.4(21.8-29.4)$ \\
\hline No motor deficit & $6.1(4.1-9.1)$ & $16.0(12.3-20.6)$ & $22.5(15.6-31.8)$ \\
\hline Motor deficit & $7.4(6.2-8.8)$ & $16.3(14.3-18.6)$ & $25.1(21.7-29.0)$ \\
\hline No incontinence & $6.4(5.2-7.9)$ & $15.6(13.4-18.0)$ & $24.9(20.9-29.3)$ \\
\hline Incontinence & $8.1(6.2-10.6)$ & $15.6(12.4-19.5)$ & $21.0(16.3-26.8)$ \\
\hline
\end{tabular}


Figure 1 shows a Kaplan-Meier plot graphically representing the risk of stroke recurrence (1-survival free of recurrent stroke) over 10 years stratified for stroke subtype.

The multivariable analyses showing variables included in the final hazards survival model for predictors of cumulative risk of stroke recurrence, are shown in Table 3. The proportional hazards assumption was shown to be fulfilled across all variables included in the model. At 1 year post-stroke, a past history of myocardial infarction and atrial fibrillation were found to be predictors of early stroke recurrence, whilst gender demonstrated borderline significance. At 5 years, prior-to-stroke hypertension and atrial fibrillation were found to be predictors, with previous myocardial infarction demonstrating borderline significance; and at 10 years, older age and a history of hypertension, myocardial infarction and atrial fibrillation diagnosed prior to first stroke, were found to be predictors of long-term stroke recurrence.

In the sensitivity analyses no significant differences in cumulative risk of recurrence were observed. Furthermore, in the multivariable analyses the predictors of recurrence remained the same while hazard ratios and corresponding confidence intervals were stable. None of the interactions tested were found to be significant except between stroke subtype at 10 years and a history of previous TIA at 10 years. There was a higher risk of recurrent stroke experienced by SAH patients who had had a previous TIA. However, this interaction was based on a very small number of patients who had a SAH and therefore our results were not reported stratified. 
Table 3:Multivariable analyses: cumulative risk of stroke recurrence at 1,5 , and 10 years*

\begin{tabular}{|c|c|c|c|c|c|c|}
\hline & \multicolumn{2}{|c|}{1 Year } & \multicolumn{2}{|c|}{5 Year } & \multicolumn{2}{|c|}{10 Year } \\
\hline & HR $(95 \% \mathrm{CI})$ & $\mathrm{P}$ value & HR (95\%CI) & $\mathrm{P}$ value & HR $(95 \%$ CI $)$ & $\mathrm{P}$ value \\
\hline \multicolumn{7}{|l|}{ Age group } \\
\hline$>65$ & 1 & 0.79 & 1 & 0.14 & 1 & $0.04^{\dagger}$ \\
\hline $65-74$ & $0.90(0.55-4.62)$ & & $1.10(0.77-1.57)$ & & $1.36(0.98-1.87)$ & \\
\hline$>75$ & $1.05(0.63-5.17)$ & & $1.37(0.99-1.91)$ & & $1.50(1.10-2.05)$ & \\
\hline \multicolumn{7}{|l|}{ Gender } \\
\hline Male & 1 & $0.07^{\dagger}$ & 1 & 0.58 & 1 & 0.48 \\
\hline Female & $1.40(0.98-2.00)$ & & $1.08(0.82-1.42)$ & & $1.09(0.85-1.41)$ & \\
\hline \multicolumn{7}{|l|}{ Ethnicity } \\
\hline White & 1 & 0.90 & 1 & 0.52 & 1 & 0.60 \\
\hline Black & $0.90(0.55-1.48)$ & & $1.20(0.85-1.68)$ & & $1.17(0.85-1.62)$ & \\
\hline Other & $1.06(0.48-2.35)$ & & $1.22(0.69-2.15)$ & & $1.15(0.66-1.98)$ & \\
\hline \multicolumn{7}{|l|}{ Socio economic status } \\
\hline Non-manual & 1 & 0.29 & 1 & 0.66 & 1 & 0.71 \\
\hline Manual & $1.25(0.82-1.90)$ & & $1.11(0.81-1.51)$ & & $1.01(0.76-1.34)$ & \\
\hline Unknown & $0.97(0.44-2.12)$ & & $0.89(0.49-1.63)$ & & $0.80(0.48-1.43)$ & \\
\hline \multicolumn{7}{|l|}{ Stroke Subtype } \\
\hline Infarct & 1 & 0.72 & 1 & 0.51 & 1 & 0.53 \\
\hline $\mathrm{PICH}$ & $1.29(0.73-2.26)$ & & $1.11(0.74-1.69)$ & & $0.99(0.66-1.48)$ & \\
\hline $\mathrm{SAH}$ & $1.05(0.31-3.57)$ & & $0.44(0.14-1.40)$ & & $0.47(0.17-1.28)$ & \\
\hline Undefined & $1.42(0.62-3.27)$ & & $1.00(0.49-2.03)$ & & $1.01(0.54-1.91)$ & \\
\hline \multicolumn{7}{|l|}{ Risk factors } \\
\hline No TIA & 1 & 0.68 & 1 & 0.19 & 1 & 0.61 \\
\hline Previous TIA & $1.11(0.69-1.78)$ & & $1.26(0.89-1.78)$ & & $1.09(0.78-1.52)$ & \\
\hline No Hypertension & 1 & 0.56 & 1 & $0.01^{\dagger}$ & 1 & $0.03^{\dagger}$ \\
\hline Hypertension & $1.12(0.76-1.65)$ & & $1.47(1.08-1.99)$ & & $1.38(1.04-1.82)$ & \\
\hline No Diabetes Mellitis & 1 & 0.79 & 1 & 0.10 & 1 & 0.14 \\
\hline Diabetes Mellitis & $1.06(0.68-1.68)$ & & $1.31(0.95-1.81)$ & & $1.26(0.93-1.71)$ & \\
\hline No MI & 1 & $0.02^{\dagger}$ & 1 & $0.09^{\dagger}$ & 1 & $0.02^{\dagger}$ \\
\hline Previous MI & $1.73(1.08-2.78)$ & & $1.39(0.95-2.03)$ & & $1.50(1.06-2.11)$ & \\
\hline No AF & 1 & $0.03^{\dagger}$ & 1 & $<0.01^{\dagger}$ & 1 & $0.01^{\dagger}$ \\
\hline Previous AF & $1.61(1.04-2.47)$ & & $1.79(1.29-2.49)$ & & $1.51(1.09-2.09)$ & \\
\hline Non-Smoker & 1 & 0.61 & 1 & 0.55 & 1 & 0.46 \\
\hline Smoker or ex-smoker & $0.90(0.60-1.35)$ & & $1.10(0.81-1.50)$ & & $1.11(0.84-1.48)$ & \\
\hline \multicolumn{7}{|l|}{ Stroke severity Indices } \\
\hline GCS $<8$ & 1 & 0.56 & 1 & 0.61 & 1 & 0.63 \\
\hline $9-12$ & $1.48(0.49-4.46)$ & & $0.99(0.44-2.23)$ & & $1.01(0.45-2.24)$ & \\
\hline $13-15$ & $1.71(0.61-4.84)$ & & $1.23(0.58-2.62)$ & & $1.21(0.59-2.48)$ & \\
\hline No motor deficit & 1 & 0.16 & 1 & 0.60 & 1 & 0.89 \\
\hline Motor deficit & $1.46(0.86-2.47)$ & & $0.91(0.64-1.30)$ & & $0.98(0.70-1.37)$ & \\
\hline No incontinence & 1 & 0.52 & 1 & 0.72 & 1 & 0.54 \\
\hline Incontinence & $1.13(0.78-1.65)$ & & $1.06(0.79-1.42)$ & & $1.10(0.82-1.48)$ & \\
\hline
\end{tabular}




\section{DISCUSSION}

This study estimated the risk of and predictors for stroke recurrence up to 10 years after initial stroke. The results show that the cumulative risk of first stroke recurrence is substantial (i.e.) up to $25 \%$ at 10 years post-initial stroke, and also identifies different predictors of stroke recurrence at 1, 5 and 10 years. No independent influence of stroke subtype or stroke severity on stroke recurrence up to 10 years was identified and no differences between ethnic groups were revealed. Risk factors prior to initial stroke were found to have a significant role in predicting stroke recurrence up to 10 years.

The results estimated no differences in risk of recurrence between stroke subtypes, with no significant differences noted between ischaemic and haemorrhagic stroke subtypes at 1, 5 and 10 years post-stroke. This contrasts with research from Japan that found the risk of stroke recurrence to be significantly greater within 1 year of the first ever stroke in patients with an initial ischaemic stroke compared with haemorrhagic stroke. However, these differences were not maintained beyond 1 year, and there were no significant differences noted during the rest of the follow-up period of 3 years ${ }^{11}$. Conversely, The Perth Community Stroke Study (PCSS) followed up 370 patients with a first-ever stroke between February 1989 and August 1990. They reported prognostic factors for recurrent stroke at 5 years including advanced age and an initial stroke subtype of either PICH or SAH, which achieved borderline significance in their analyses ${ }^{12}$.

This study found no differences between markers of stroke severity as predictors of stroke recurrence at any time point. In contrast, baseline results from the African-American Antiplatelet Stroke Prevention Study (AAAPS) found that stroke severity and disability at the time of initial event, were significantly associated with increases in stroke recurrence in black 
patients during 2 years of follow-up ${ }^{13}$. Work previously described by the SLSR has shown that black patients maintain a higher initial stroke risk than white patients ${ }^{7}$, yet these results indicate that this increased risk does not confer an increased suspectibility to stroke recurrence amongst our black population. It has been shown both the SLSR as well as by the Northern Manhattan Stroke Study that different risk factors and co-morbidities may be important in black and white patients ${ }^{14 ; 15}$ and we have previously demonstrated increased survival after first stroke in black patients compared to white patients over 65 years ${ }^{16}$. This study importantly shows that these survival differences are not caused by differences in stroke recurrences between these ethnic groups.

This study found the cumulative risk of recurrence to be $7 \%$ at 1 year, $16 \%$ at 5 years and $25 \%$ at 10 years. Previous studies show much variation in the cumulative risk of stroke recurrence. At 1 year the risk of recurrence ranges from $4.7 \%$ in the Netherlands ${ }^{3}$ to $14 \%$ described by different groups both based in Sweden ${ }^{17 ; 18}$. For many studies the risk of stroke recurrence lies between $9-12 \%$ at 1 year ${ }^{6 ; 19-23}$ which is greater than the rate of $7 \%$ found in this study at 1 year. Studies have shown the 5 year risk of stroke recurrence to range from 12$42 \%^{2 ; 3}$ with other population-based studies reporting cumulative risk of $19 \%$ in Manhattan, $29 \%$ in Rochester, $30 \%$ in Oxfordshire and $32 \%$ in Perth up to 5 years after initial stroke $e^{5 ; 6 ; 24 ; 25}$. By 10 years, the risk of stroke recurrence reported in other studies is wideranging from $16.9 \%$ in $\mathrm{Sweden}^{26}, 43 \%$ in $\mathrm{Perth}^{27}, 51.3 \%$ in $\mathrm{Japan}^{28}$, and 53.9\% in Sweden ${ }^{18}$.

The results, whilst within the ranges described above, are lower than other studies with comparable follow-up periods. Studies differ in the definition of a stroke used by the investigators. For example, results from Spain demonstrated recurrence rates of $9.5 \%$ at 1 year and $26 \%$ at 5 years post-initial stroke. This study excluded patients with a SAH 
subtype $^{19}$. In our study SAH confer an increased risk of recurrence in the very early period of weeks to months, after an initial stroke, after which there is no increase in risk of stroke recurrence up to 10 years of follow-up. By excluding this subgroup, artificially higher rates of recurrence may have been achieved in these studies.

Differing rates of risk may be explained by different definitions of stroke recurrence used between studies as case ascertainment criteria. The Oxford Community Stroke Project followed up patients for 6.5 years and found a cumulative risk of recurrence of $30 \%$ at 5 years $^{25}$. The methodology used by the OCSP investigators however, was very different to our methods as they included transient ischaemic attacks occurring in the follow-up period as a recurrent event ${ }^{25}$. Furthermore, we defined a recurrent stroke as occurring 21 days after the initial event unless in a different vascular territory, however, many studies include all strokes after the initial event ${ }^{6 ; 18 ; 19 ; 24 ; 28 ; 29}$. It has been demonstrated by the VISION investigators that a high proportion of patients with minor stroke have both clinical and radiological recurrences in the same vascular territory as their initial event in the first days after their stroke, whilst recurrent events outside of the initial vascular territory or perfusion defect were rare $^{30}$. It has also been demonstrated previously that different definitions of stroke recurrence constitute wide ranging rates of risk of stroke recurrence in the short term ${ }^{31}$.

The results of this study demonstrate the importance of management of co-morbidities and traditional vascular risk factors present at the time of the initial stroke, as predictors of stroke at 1, 5 and 10 years. At 1 year, atrial fibrillation and myocardial infarction were identified as predictors of stroke recurrence. This is also demonstrated in results from the FINMONICA Stroke Register, which identified myocardial infarction and atrial fibrillation to be independent predictors of stroke recurrence at 1 year in patients ages 75 years and over ${ }^{32}$. 
Results from the Nanjing Stroke Registry showed hypertension, atrial fibrillation and smoking to be predictors of stroke recurrence at 1 year, however we found hypertension only to become a significant predictor of recurrence during later follow-up, and smoking to not be a predictor at any time-point investigated ${ }^{20}$.

Hypertension and atrial fibrillation have been shown to be predictors for stroke recurrence up to 5 years post-stroke. There is much variation in previously reported literature regarding predictors for stroke recurrence beyond 1 year post-stroke. Diabetes has been shown in studies to be a predictor for stroke recurrence beyond 1 year ${ }^{12 ; 33}$, and up to 10 years in patients with a first cerebral infarction ${ }^{6}$. The Lehigh Valley Recurrent Stroke Study found a past history of hypertension prior to initial stroke, and a history of transient ischaemic attack (TIA) after the initial stroke to be independent predictors for stroke recurrence up to 5 years. However, similar to our results, they also found that a past history of TIA prior to initial stroke was not a predictor of stroke recurrence ${ }^{34 ; 35}$.

The results demonstrate the importance of cardiovascular risk factors throughout the followup period, and supplement previous work identifying the importance of cardiovascular disease on long-term outcomes after first stroke ${ }^{36}$. In this study, atrial fibrillation and myocardial infarction were predictors for stroke recurrence throughout the follow-up period up to 10 years, although previous myocardial infarction had only borderline significance in the middle term period. Atrial fibrillation and myocardial infarction are known to be associated with cardioembolic strokes which have the highest stroke recurrence rates amongst the aetiological subtypes ${ }^{37}$. Hypertension, which gained importance as a predictor for stroke recurrence in the middle and long term periods, is associated with small vessel disease which has been shown to be the aetiological cause related to lacunar infarcts ${ }^{38}$. Therefore, patients 
with small vessel disease have a lower risk of stroke recurrence at 1 year, and may experience stroke recurrence later than other stroke subtypes.

This study had strengths and limitations. The main strengths lie in study design as by conducting a population based study we have an unbiased sampling frame. Very long-term estimates for stroke recurrence up to 10 years after initial stroke have been provided, using standardised methods for comparability to other studies. However, discrepancies in completeness of case detection of both initial and recurrent stroke, may affect the study as very mild strokes which may not present to primary or secondary care services may be missed. Furthermore, the definition of stroke recurrence excludes strokes in the same vascular territory within the first 21 days after the initial event. By definition, this study is therefore lacking data on early strokes.

In order to be comparable to previously published long-term data, stroke subtype was defined according to a pathological classification in this study. Therefore this study lacks data on stroke aetiology. We have previously proposed and published an aetiological classification system for ischaemic stroke ${ }^{39}$, modified from the TOAST classification to account for expected differences in aetiology within the multi-ethnic population of South London, and this is currently in use within the SLSR. Having now identified initial predictors of stroke recurrence up to the long-term period, further investigation of the effect of aetiological factors on stroke recurrence is now needed.

In summary, this study investigates the risk of and predictors for the very long term risk of stroke recurrence up to 10 years post-stroke. By demonstrating different predictors for stroke recurrence in the early, medium and long-term period, we have highlighted the long-term 
commitment needed to modify cardiovascular risk factors, both prior to stroke, and after stroke in order to protect patients from stroke recurrence. Further investigation of the impact of stroke aetiology on stroke recurrence in the early, middle and long term periods, and the impact of appropriate treatment on risk factors up to 10 years after initial stroke is indicated.

\section{Acknowledgements}

We thank all the patients and their families and the health care professionals involved.

Particular thanks to all the fieldworkers and the whole team who have collected data since 1995 for the South London Stroke Register.

The Corresponding Author has the right to grant on behalf of all authors and does grant on behalf of all authors, an exclusive licence (or non-exclusive for government employees) on a worldwide basis to the BMJ Publishing Group Ltd and its Licensees to permit this article (if accepted) to be published in Journal of Neurology, Neurosurgery \& Psychiatry and any other BMJPGL products to exploit all subsidiary rights, as set out in our licence (http://jnnp.bmj.com/ifora/licence.pdf).

\section{Competing interests}

A.P.G has consultancy agreements with Pfizer Global R\&D, Takeda Global R\&D (Europe), Schwarz Biosciences, Solace Pharmaceuticals, Cytel Novartis, and Organon. The remaining authors report no conflicts.

\section{Funding}

This study was funded by the Stanley Thomas Johnson Foundation, the Northern and Yorkshire NHS R\&D Programme in Cardiovascular Disease and Stroke, the Department of Health UK, and Guy's and St. Thomas' Hospital Charity. The authors acknowledge financial 
support from the Department of Health via the National Institute for Health Research (NIHR) Biomedical Research Centre and the Programme Grant award to Guy's and St. Thomas' NHS Foundation Trust in partnership with King's College London (RP-PG-0407-10184). 
Reference List

1. Bonita R. Epidemiology of stroke. Lancet 1992;339:342-4.

2. Sacco RL, Wolf PA, Kannel WB, McNamara PM. Survival and recurrence following stroke. The Framingham study. Stroke 1982;13:290-5.

3. van W, I, Kappelle LJ, van GJ, Koudstaal PJ, Franke CL, Vermeulen M, Gorter JW, Algra A. Long-term survival and vascular event risk after transient ischaemic attack or minor ischaemic stroke: a cohort study. Lancet 2005;365:2098-104.

4. Hillen T, Coshall C, Tilling K, Rudd AG, McGovern R, Wolfe CD. Cause of stroke recurrence is multifactorial: patterns, risk factors, and outcomes of stroke recurrence in the South London Stroke Register. Stroke 2003;34:1457-63.

5. Hardie K, Jamrozik K, Hankey GJ, Broadhurst RJ, Anderson C. Trends in five-year survival and risk of recurrent stroke after first-ever stroke in the Perth Community Stroke Study. Cerebrovasc Dis 2005;19:179-85.

6. Petty GW, Brown RD, Jr., Whisnant JP, Sicks JD, O'Fallon WM, Wiebers DO. Survival and recurrence after first cerebral infarction: a population-based study in Rochester, Minnesota, 1975 through 1989. Neurology 1998;50:208-16.

7. Heuschmann PU, Grieve AP, Toschke AM, Rudd AG, Wolfe CD. Ethnic group disparities in 10-year trends in stroke incidence and vascular risk factors: the South London Stroke Register (SLSR). Stroke 2008;39:2204-10.

8. Tilling K, Sterne JA, Wolfe CD. Estimation of the incidence of stroke using a capturerecapture model including covariates. Int.J.Epidemiol. 2001;30:1351-9. 
9. Arterial hypertension. Report of a WHO expert committee. World Health Organ Tech.Rep.Ser. 1978;7-56.

10. Pal J, Brown R, Fleiszer D. The value of the Glasgow Coma Scale and Injury Severity Score: predicting outcome in multiple trauma patients with head injury. J.Trauma 1989;29:746-8.

11. Yokota C, Minematsu K, Hasegawa Y, Yamaguchi T. Long-term prognosis, by stroke subtypes, after a first-ever stroke: a hospital-based study over a 20-year period. Cerebrovasc.Dis. 2004;18:111-6.

12. Hankey GJ, Jamrozik K, Broadhurst RJ, Forbes S, Burvill PW, Anderson CS, StewartWynne EG. Long-term risk of first recurrent stroke in the Perth Community Stroke Study. Stroke 1998;29:2491-500.

13. Ruland S, Richardson D, Hung E, Brorson JR, Cruz-Flores S, Felton WL, III, FordLynch G, Helgason C, Hsu C, Kramer J, Mitsias P, Gorelick PB. Predictors of recurrent stroke in African Americans. Neurology 2006;67:567-71.

14. Hajat C, Dundas R, Stewart JA, Lawrence E, Rudd AG, Howard R, Wolfe CD. Cerebrovascular risk factors and stroke subtypes: differences between ethnic groups. Stroke 2001;32:37-42.

15. Sacco RL, Boden-Albala B, Abel G, Lin IF, Elkind M, Hauser WA, Paik MC, Shea S. Race-ethnic disparities in the impact of stroke risk factors: the northern Manhattan stroke study. Stroke 2001;32:1725-31. 
16. Wolfe CD, Smeeton NC, Coshall C, Tilling K, Rudd AG. Survival differences after stroke in a multiethnic population: follow-up study with the South London stroke register. BMJ 2005;331:431.

17. Viitanen M, Eriksson S, Asplund K. Risk of recurrent stroke, myocardial infarction and epilepsy during long-term follow-up after stroke. Eur.Neurol. 1988;28:227-31.

18. Eriksson SE, Olsson JE. Survival and recurrent strokes in patients with different subtypes of stroke: a fourteen-year follow-up study. Cerebrovasc.Dis. 2001;12:171-80.

19. Modrego PJ, Mainar R, Turull L. Recurrence and survival after first-ever stroke in the area of Bajo Aragon, Spain. A prospective cohort study. J.Neurol.Sci. 2004;224:49-55.

20. Xu G, Liu X, Wu W, Zhang R, Yin Q. Recurrence after ischemic stroke in chinese patients: impact of uncontrolled modifiable risk factors. Cerebrovasc.Dis. 2007;23:11720.

21. Appelros P, Nydevik I, Seiger A, Terent A. Predictors of severe stroke: influence of preexisting dementia and cardiac disorders. Stroke 2002;33:2357-62.

22. Sacco RL, Shi T, Zamanillo MC, Kargman DE. Predictors of mortality and recurrence after hospitalized cerebral infarction in an urban community: the Northern Manhattan Stroke Study. Neurology 1994;44:626-34.

23. Ryglewicz D, Baranska-Gieruszczak M, Czlonkowska A, Lechowicz W, Hier DB. Stroke recurrence among 30 days survivors of ischemic stroke in a prospective community-based study. Neurol.Res. 1997;19:377-9. 
24. Dhamoon MS, Sciacca RR, Rundek T, Sacco RL, Elkind MS. Recurrent stroke and cardiac risks after first ischemic stroke: the Northern Manhattan Study. Neurology 2006;66:641-6.

25. Burn J, Dennis M, Bamford J, Sandercock P, Wade D, Warlow C. Long-term risk of recurrent stroke after a first-ever stroke. The Oxfordshire Community Stroke Project. Stroke 1994;25:333-7.

26. Li C, Hedblad B, Rosvall M, Buchwald F, Khan FA, Engstrom G. Stroke incidence, recurrence, and case-fatality in relation to socioeconomic position: a population-based study of middle-aged Swedish men and women. Stroke 2008;39:2191-6.

27. Hardie K, Hankey GJ, Jamrozik K, Broadhurst RJ, Anderson C. Ten-year risk of first recurrent stroke and disability after first-ever stroke in the Perth Community Stroke Study. Stroke 2004;35:731-5.

28. Hata J, Tanizaki Y, Kiyohara Y, Kato I, Kubo M, Tanaka K, Okubo K, Nakamura H, Oishi Y, Ibayashi S, Iida M. Ten year recurrence after first ever stroke in a Japanese community: the Hisayama study. J.Neurol.Neurosurg.Psychiatry 2005;76:368-72.

29. Cheung CM, Tsoi TH, Hon SF, Au-Yeung M, Shiu KL, Lee CN, Huang CY. Outcomes after first-ever stroke. Hong.Kong.Med J 2007;13:95-9.

30. Coutts SB, Hill MD, Campos CR, Choi YB, Subramaniam S, Kosior JC, Demchuk AM. Recurrent events in transient ischemic attack and minor stroke: what events are happening and to which patients? Stroke 2008;39:2461-6.

31. Coull AJ, Rothwell PM. Underestimation of the early risk of recurrent stroke: evidence of the need for a standard definition. Stroke 2004;35:1925-9. 
32. Kaarisalo MM, Immonen-Raiha P, Marttila RJ, Lehtonen A, Salomaa V, Sarti C, Sivenius J, Torppa J, Tuomilehto J. Atrial fibrillation in older stroke patients: association with recurrence and mortality after first ischemic stroke. J.Am.Geriatr.Soc. 1997;45:1297-301.

33. Elneihoum AM, Goransson M, Falke P, Janzon L. Three-year survival and recurrence after stroke in Malmo, Sweden: an analysis of stroke registry data. Stroke 1998;29:2114-7.

34. Alter M, Friday G, Lai SM, O'Connell J, Sobel E. Hypertension and risk of stroke recurrence. Stroke 1994;25:1605-10.

35. Friday G, Alter M, Lai SM, Sobe E. Transient ischemic attack and risk of stroke recurrence: The Lehigh Valley Recurrent Stroke Study. J.Stroke Cerebrovasc.Dis. 1997;6:410-5

36. Hankey GJ. Long-term outcome after ischaemic stroke/transient ischaemic attack. Cerebrovasc.Dis. 2003;16 Suppl 1:14-9.

37. Kolominsky-Rabas PL, Weber M, Gefeller O, Neundoerfer B, Heuschmann PU. Epidemiology of ischemic stroke subtypes according to TOAST criteria: incidence, recurrence, and long-term survival in ischemic stroke subtypes: a population-based study. Stroke 2001;32:2735-40.

38. Adams HP, Jr., Bendixen BH, Kappelle LJ, Biller J, Love BB, Gordon DL, Marsh EE, III. Classification of subtype of acute ischemic stroke. Definitions for use in a multicenter clinical trial. TOAST. Trial of Org 10172 in Acute Stroke Treatment. Stroke 1993;24:35-41. 
39. Hajat C, Coshall C, Rudd AG, Patel M, Bhalla A, Howard R, Wolfe CD. The inter- and intraobserver reliabilities of a new classification system for ischaemic stroke: the South London Stroke Register. J.Neurol.Sci. 2001;190:79-85. 


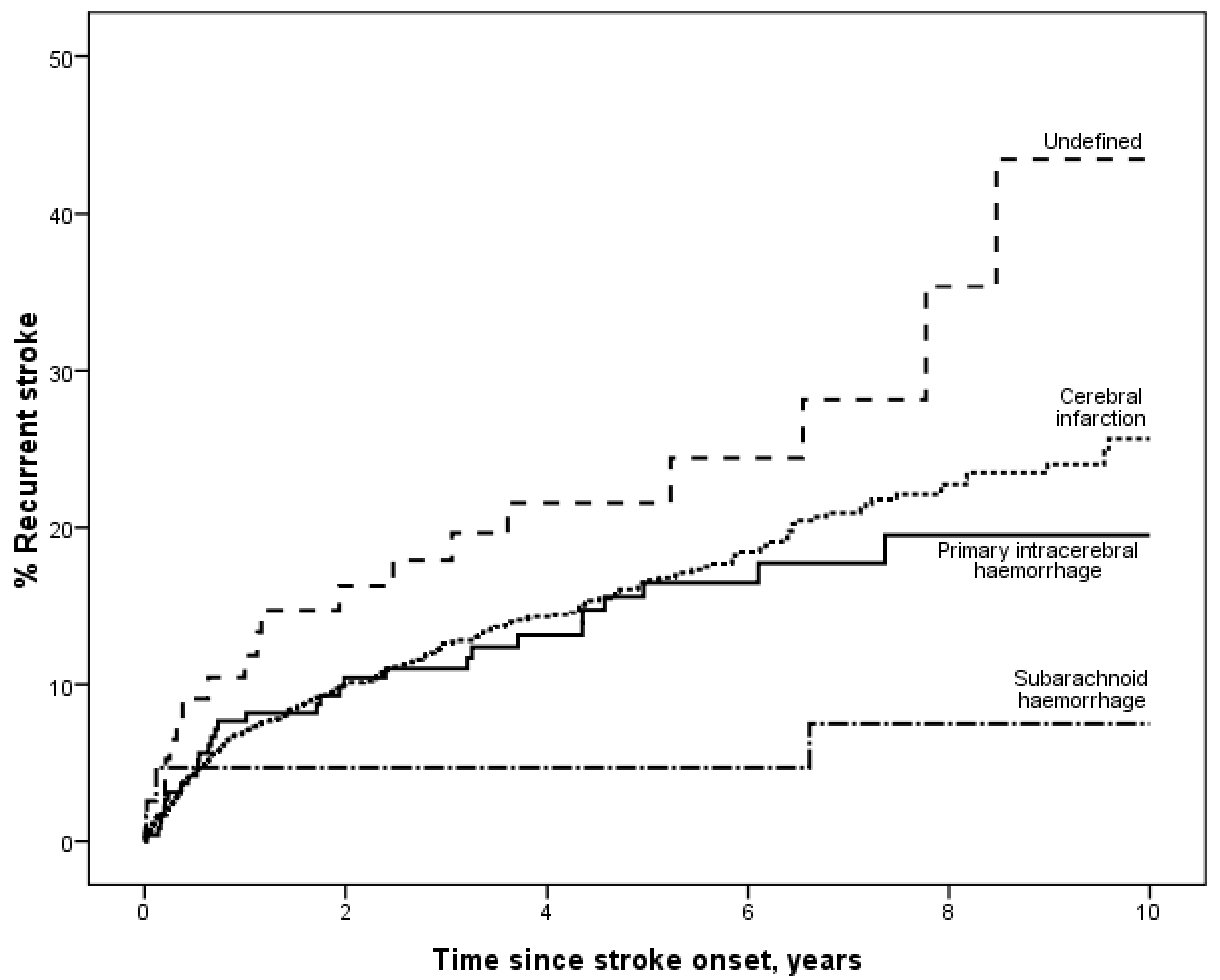

Figure 1: Cumulative risk of stroke recurrence stratified according to stroke subtype 